\title{
Compatibility of Trichoderma harzianum (KBN-29) with Selected inorganic Fertilizers: An In vitro Study
}

\author{
Kishor Chand Kumhar ${ }^{1 *}$, A. Babu', John Peter $^{2}$, M. Bordoloi ${ }^{1}$, Hirakjyoti Rajbongshi ${ }^{1}$, \\ Sarvesh Singh Yadav ${ }^{1}$, Swagata Mani ${ }^{1}$ and Pritam Dey ${ }^{1}$ \\ ${ }^{1}$ Tea Research Association, North Bengal Regional Research and Development Centre, \\ Nagrakata, District - Jalpaiguri, West Bengal 735 225, India \\ ${ }^{2}$ Varsha Bioscience and Technology India Pvt. Ltd. \# 253/A, Jiblakpally Village, Pochampally \\ Mandal, Nalgonda, Hyderabad - 508284, Telangana, India \\ *Corresponding author
}

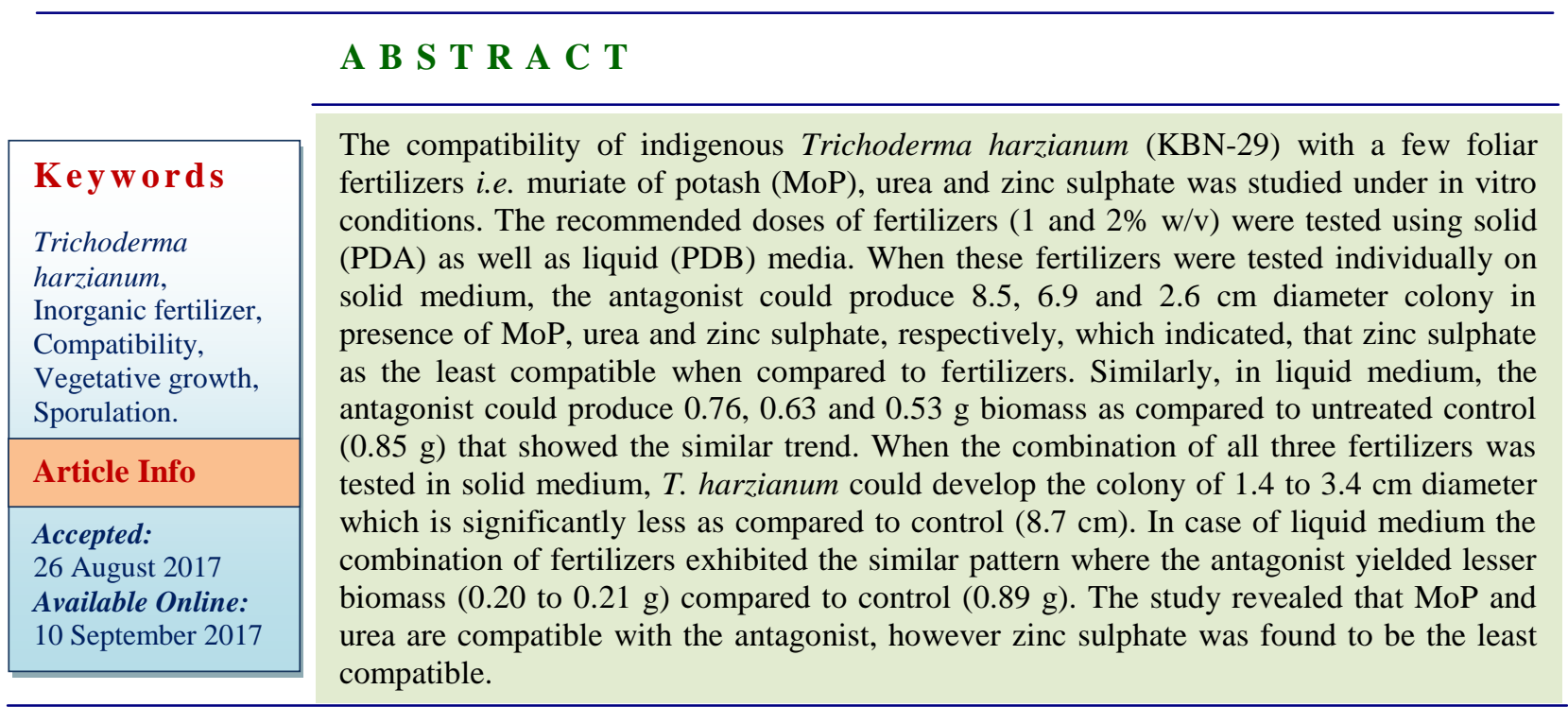

\section{Introduction}

Genus Trichoderma is one of the most important beneficial fungi, amongst the known fungal flora. Different formulations of Trichoderma spp have been applied in the tea crop to protect the tea plantation from several fungal phytopathogens. It is well established that, this fungus has the ability to control a wide array of fungal phytopathogens, such as Fusarium sp, Pythium sp., Rhizoctonia solani Kühn, Sclerotium rolfsii Sacc, Macrophomina phaseolina etc (Muhammad and Amusa,
2003; Sivan et al., 1987, Adekunle et al., 2006, Shalini et al., 2006; Elad et al., 1980, Upadhyay and Mukhopadhyay, 1986; Sivan et al., 1984, Howell 1982).

In general, certain inorganic fertilizers have also been applied as foliar spray on tea crop (Camellia sp) for better yield (Fan et al., 2005; Drinnan, 2008). The application of such fertilizers ensures the adequate nutrient availability to the crop which ultimately 
influences both yield and its quality (Anonymous, 2002). Often, these fertilizers are applied to the soil, however, under certain circumstances especially during stress conditions, fertilizers such as, urea, DAP, muriate of potash $(\mathrm{MoP})$, zinc sulphate $\left(\mathrm{ZnSO}_{4}\right)$, manganese sulphate $\left(\mathrm{MgSO}_{4}\right)$ etc. have also been applied as foliar spray to fulfill the immediate nutritional requirement of the tea plant. The combined application of urea, zinc sulphate and boric acid as foliar spray enhances the growth and development of crop plants (Amin and Shahsavar, 2012).

The performance of Trichoderma spp. under the lab as well as field condition is dependent on its growth and sporulation potential, which is affected by numerous factors such as $\mathrm{pH}$, temperature, RH etc (Reetha et al., 2014). It has been reported that certain inorganic fertilizers also have adverse effect on the growth and development of this antagonist to variable extent (Shylaja and Rao, 2012; Mondal, 2012; Gampala and Pinnamaneni, 2010, Bhai and Thomas, 2010).

The present study was carried out to determine the compatibility of $T$. harzianum with selected foliar fertilizers to find out whether they have any adverse effect on its performance with an ultimate aim to incorporate both antagonist and fertilizers in integrated crop improvement strategies in tea plantation.

\section{Materials and Methods}

\section{Procurement of Trichoderma harzianum and fertilizers}

The strain of antagonist, T. harzianum (KBN29) has been isolated and developed at the Department of Mycology \& Microbiology, Tea Research Association, North Bengal Regional R \& D centre, Nagrakata, West Bengal, India. The required fertilizers were purchased from the local market.

\section{Determination of effect of fertilizers on T. harzianum}

\section{Effect of individual fertilizer}

The poisoned food technique (Nene and Thapliyal, 1993) was employed to determine the effect of selected fertilizers on growth and development of local antagonistic strain of $T$. harzianum. All the fertilizers were assessed at two different doses i.e. 1 and $2 \%(\mathrm{w} / \mathrm{v})$. The required quantities of MoP, urea and zinc sulphate were measured using the weighing balance (Mettler-ME204), and used for the laboratory assays.

\section{Preparation of media to study the effect of individual fertilizer}

\section{Solid medium}

In case of solid medium culture, the potato dextrose agar (PDA) medium was sterilized in the autoclave and required quantities of fertilizers were added separately in to it at its lukewarm state followed by proper mixing.

Then the medium was poured in to Petri plates (15-20 mL medium per plate). After solidification, five millimeter discs of actively growing $T$. harzianum were inoculated in to the centre of plates and incubated at $26 \pm 2{ }^{\circ} \mathrm{C}$ in BOD incubator. Three replications per treatment were maintained and completely randomized design (CRD) was followed. When the control plates were fully covered with mycelial growth of antagonist, the colony diameter was measured from all other treatments. Finally, per cent growth inhibition over control was calculated by applying the formula of Vincent (1947).

\section{Liquid medium}

In second method, i.e. liquid medium culture, one hundred milliliter of potato dextrose broth (PDB) was taken in to $250 \mathrm{~mL}$ capacity 
conical flask and sterilized using autoclave. After sterilization, the required quantities of fertilizers were added in to the flasks, separately when the medium was in lukewarm state. The flasks were inoculated with $5 \mathrm{~mm}$ mycelial discs of $T$. harzianum followed by incubation for 7 days.

To assess the quantity of biomass produced, the whole culture along with medium was filtered through Whatman filter paper number 1 and the retained biomass on filter paper was subjected to dry in an oven for a period of 6 $\mathrm{hr}$ at $60{ }^{\circ} \mathrm{C}$ and finally the biomass was determined using electric weighing balance.

\section{Preparation of media to study the effect of fertilizer combinations}

For required concentrations ( 1 and $2 \%$ ), the quantities of the fertilizers were measured and simultaneously mixed with the pre- sterilized medium, homogeneously. The remaining procedure was same as described in the above experiments. All the experiments were replicated thrice.

\section{Statistical analysis}

To find out critical difference among the treatments, data were statistically analyzed through online package OPSTAT of Chaudhary Charan Singh, Haryana Agricultural University, Hisar, Haryana, India (www.hua.ernet.in).

\section{Results and Discussion}

The results of the experiments on individual fertilizer on solid medium indicated that, $T$. harzianum started growing within $24 \mathrm{hr}$ of inoculation in each treatment except that of plates treated with zinc sulphate (Fig. 1). After $120 \mathrm{hr}$, the antagonist achieved its full growth in all the treatments except zinc sulphate treatment, which revealed that zinc sulphate had adverse effect on the antagonist (plate $1 \mathrm{~A}$ ). However, in case of other two fertilizers i.e. MoP and urea, both were found to be compatible and comparatively safer to this antagonist (Table 1).

When the same concentrations of these fertilizers were evaluated using broth culture medium, similar trend of growth pattern and conidial production was observed (plate 1B). The $T$. harzianum could produce the highest biomass $(0.85 \mathrm{~g})$ in control. Amongst the other treatments, MoP was observed to be the safest one followed by urea, and hence the antagonist could produce 0.76 and $0.63 \mathrm{~g}$ biomass at $1 \%$ concentration of $\mathrm{MoP}$ and urea, respectively. The biomass production was slightly lesser at their higher concentrations and all the treatments were statistically non-significant with each other (Table 2).

The combination of these three fertilizers showed the adverse effect on growth and sporulation of $T$. harzianum in both media. In case of PDA, the antagonist could produce only 3.4 and $1.4 \mathrm{~cm}$ diameter colonies at 1 and $2 \%$ concentrations, respectively, which were smaller as compared to that of the control $(8.7 \mathrm{~cm})$ as indicated in figure 2 and plate $1 \mathrm{C}$.

In this experiment the per cent growth inhibition of $T$. harzianum due to combination of fertilizers was 61.1 and 84.0 at lower (1\%) and higher (25\%) concentrations, respectively.

Similar growth inhibitory effect was also exhibited by the antagonist when it was tested in liquid culture medium admixed with all three fertilizers (plate 1D). The antagonist produced very less amount of biomass $(0.20$ to $0.21 \mathrm{~g}$ ) as compared to untreated control $(0.89 \mathrm{~g})$, resulting in 76.7 to 77.3 per cent reduction in biomass production over control. 
Fig. 1: In vitro effect of inorganic fertilizers on growth of $T$. harzianum

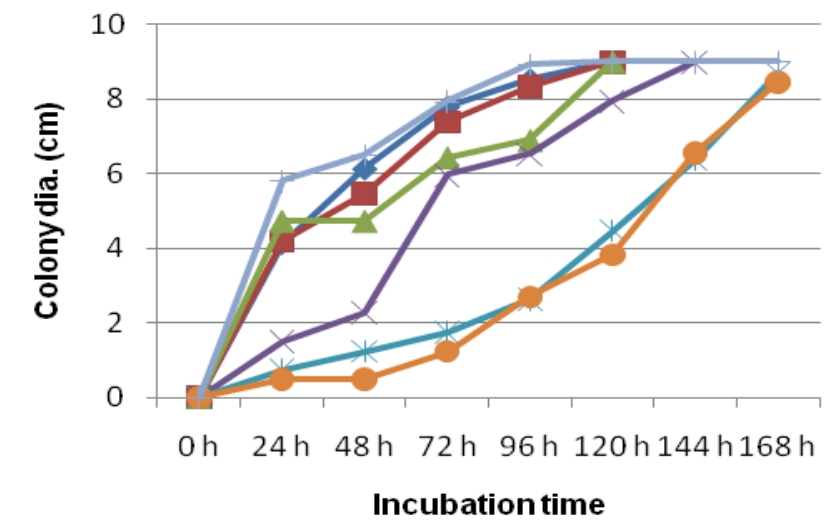

$\longrightarrow-T h+$ MOP @ $1 \%$

- - Th + MOP @ 2\%

- Th + Urea @ 1\%

$\longrightarrow$ Th + Urea @ 2\%

- $\mathrm{Th}+\mathrm{ZnSo4} @ 1 \%$

- Th + ZnSo4 @ 2\%

T. harzianum alone

Incubation time

Fig. 2: In vitro effect of combination of MoP, urea and zinc sulphate on growth of $T$. harzianum on solid medium

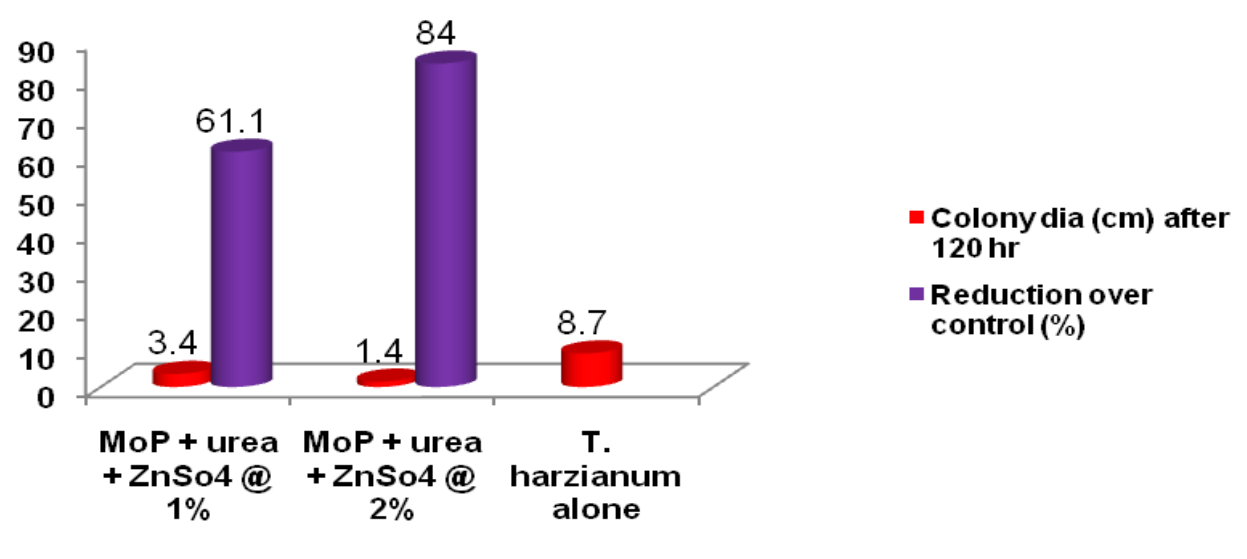

Fig. 3: In vitro effect of combination of MoP, urea and zinc sulphate on growth of $T$. harzianum on liquid medium

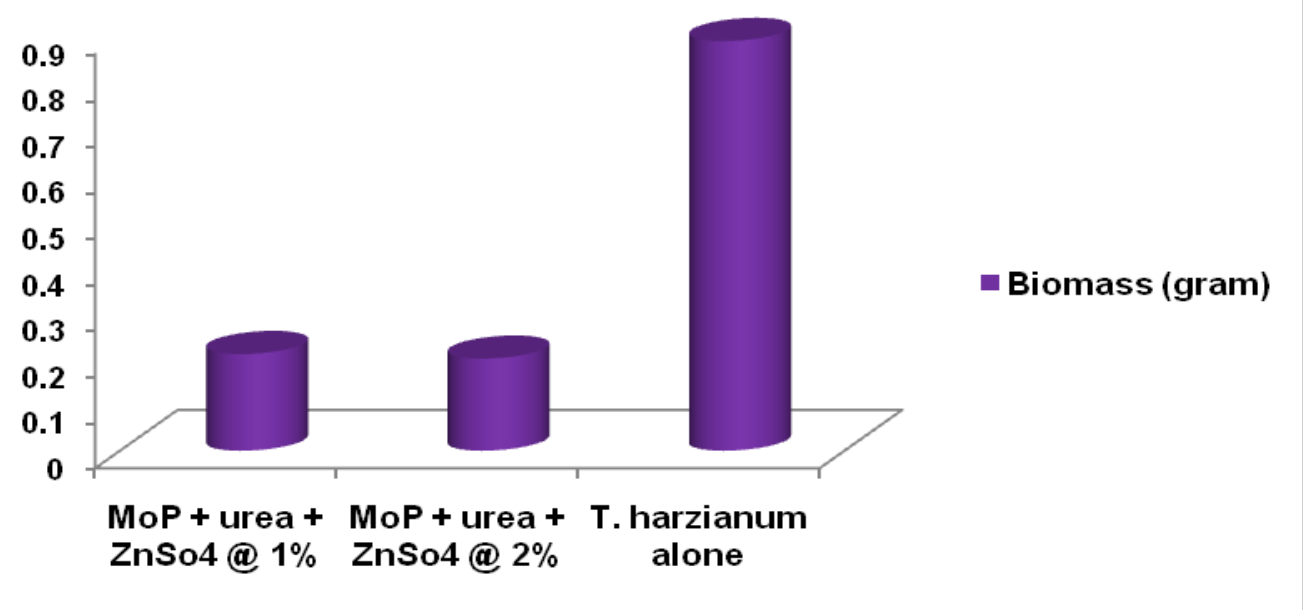



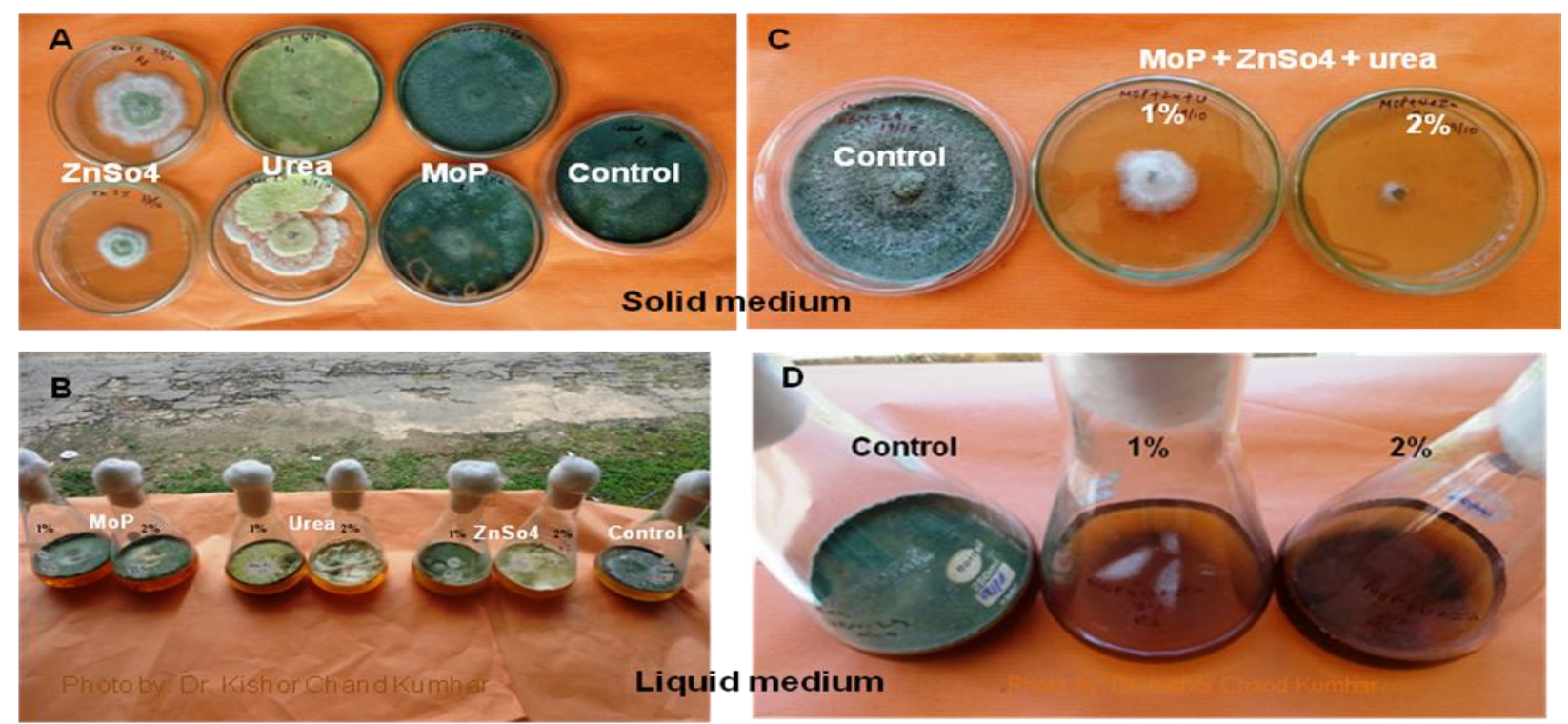

Plate 1: In vitro effect of individual and combination of fertilizers on growth and sporulation of $T$. harzianum (A \& B: individual fertilizers and C \& D: combination of MoP + urea + zinc sulphate)

Table.1 Effect of fertilizers on growth and sporulation of T. harzianum

\begin{tabular}{|l|l|l|l|}
\hline \multirow{2}{*}{ T. harzianum + fertilizer combination } & \multicolumn{2}{|c|}{ Mean colony diameter \pm S.E.* } & \multirow{2}{*}{$\begin{array}{c}\text { Sporulation status } \\
\text { after 15 days }\end{array}$} \\
\cline { 2 - 3 } & \multicolumn{1}{|c|}{ after 120 hr } & After 168 Hr & +++ \\
\hline Th + MOP @ 1\% & $8.5 \pm 0.3$ & $9.0 \pm 0.0$ & ++ \\
\hline Th + MOP @ 2\% & $8.3 \pm 0.1$ & $9.0 \pm 0.0$ & +++ \\
\hline Th + Urea @ 1\% & $6.9 \pm 0.1$ & $9.0 \pm 0.0$ & +++ \\
\hline Th + Urea @ 2\% & $6.5 \pm 0.1$ & $9.0 \pm 0.0$ & +++ \\
\hline Th + ZnSo4 @ 1\% & $2.6 \pm 0.3$ & $8.7 \pm 0.2$ & ++ \\
\hline Th + ZnSo4 @ 2\% & $2.7 \pm 0.2$ & $8.5 \pm 0.3$ & ++ \\
\hline T. harzianum alone & $8.9 \pm 0.1$ & $9.0 \pm 0.0$ & +++ \\
\hline CD & 0.5 & 0.4 & \\
\hline SE $(\mathrm{d})$ & 0.2 & 0.2 & \\
\hline SE $(\mathrm{m})$ & 0.2 & 0.1 & \\
\hline CV & 4.6 & 2.4 & \\
\hline
\end{tabular}

*Mean of 3 replications \pm SE, $+++=$ excellent, and $++=$ good

Table.2 Effect of fertilizers on T. harzianum in liquid culture medium

\begin{tabular}{|l|c|}
\hline \multicolumn{1}{|c|}{ T. harzianum and fertilizer combination } & Dry biomass weight $(\mathbf{g})$ produced in PDB \pm SE* \\
\hline Th + MOP @ 1\% & $0.76 \pm 0.11$ \\
\hline Th + MOP @ 2\% & $0.70 \pm 0.17$ \\
\hline Th + Urea @ 1\% & $0.63 \pm 0.12$ \\
\hline Th + Urea @ 2\% & $0.59 \pm 0.06$ \\
\hline Th + ZnSo4 @ 1\% & $0.53 \pm 0.16$ \\
\hline Th + ZnSo4 @ 2\% & $0.43 \pm 0.09$ \\
\hline T. harzianum alone & $0.85 \pm 0.19$ \\
\hline CD & NS \\
\hline SE $(m)$ & 0.14 \\
\hline SE $(d)$ & 0.19 \\
\hline
\end{tabular}

*Mean of 3 replications $\pm \mathrm{SE}$ 
Gampala and Pinnamaneni (2010) investigated the effect of certain inorganic fertilizers such as urea $(10 \mathrm{~g} / \mathrm{L})$, muriate of potash $(20 \mathrm{~g} / \mathrm{L})$ and super phosphate $(20 \mathrm{~g} / \mathrm{L})$ using solid as well as liquid media and reported that muriate of potash and super phosphate were more compatible than that of urea. Shylaja and Rao (2012) tested the compatibility of $T$. harzianum with urea, single super phosphate (SSP), muriate of potash (MoP) and calcium ammonium nitrate (CAN) at different concentrations under lab conditions, and they found that the urea and MoP were compatible to the antagonist. However, both SSP and calcium ammonium nitrate were reported to inhibit the growth. These findings are in tune with our present findings. Similarly, Mondal (2012) assessed the compatibility of $T$. harzianum with zinc sulphate heptahydrate and observed that $T$. harzianum could exhibit significantly higher survival in the presence of zinc sulphate up to concentration of $150 \mathrm{ppm}$ beyond this concentration there was some gradual decline in its viability. Our present findings would certainly be useful to the planters for taking decisions about the combined application of these fertilizers with the antagonist under field conditions.

\section{Acknowledgements}

The authors are thankful to Dr. T. Prameela Devi, Principal Scientist, Department of Mycology \& Plant Pathology, Indian Agricultural Research Institute, PUSA, New Delhi, for identifying the indigenous $T$. harzianum. Our sincere thanks are also due to Bioserve Biotechnologies (India) Pvt. Ltd, Hyderabad, for DNA finger printing of the antagonistic strain to re-confirm its identity. The financial support rendered in the form of a research project from the Biotechnology Industry Research Assistance Council (BIRAC), New Delhi is also gratefully acknowledged.

\section{References}

Adekunle, A. T., Ikotun, T., Florini, D. A. and Cardwell, K. F. 2006. Field evaluation of selected formulations of Trichoderma sp. as seed treatment to control damping-off of cowpea caused by Macrophomina phaseolina. African Journal of Biotechnology. 5: 419-424.

Amin, P. S., and Shahsavar, A. R. 2012. The influence of urea, boric acid and zinc sulphate on vegetative traits of olive. Journal of Biodiversity and Environmental Sciences. 6(16): 109113.

Anonymous, 2002. Tea Growers Hand Book. $5^{\text {th }}$ Edition, Tea Research Foundation of Kenya, Elizer Services Publishers, Times Printing Services, Nairobi.

Bhai, R. S., and Thomas, J. 2010. Compatibility of Trichoderma harzianum (Rifai.) with fungicides, insecticides and fertilizers. Indian Phytopathology. 63 (2): 145-148.

Drinnan, E., 2008 Fertilizer Strategies for Mechanical Tea Production. RIRDC Publication No. 08/030.

Elad, Y., Chet, I. and Katan, J. 1980. Trichoderma harzianum: A biocontrol agent effective against Sclerotium rolfsii and Rhizoctonia solani. Phytopathology.70: 119-121.

Fan, S., Fu, L., Chen, H., Hong L., and Wang P. 2005. Balanced fertilization for tea production in Yunnan. Better Crops. 89(2): 25-27.

Gampala, K., and Pinnamaneni, R. S. 2010. Studies on the compatibility of Trichoderma viride with certain Agrochemicals. Current World Environment. 5(1): 155-158.

Howell, C. R., 1982. Effect of Gliocladium virens on Pythium ultimum, Rhizoctonia solani and damping-off of cotton seedlings. Phytopathology. 72: 496-498.

Mondal, P., 2012. Integrated formulation of 
neem oil, Trichoderma harzianum and zinc for management of sheath blight and zinc in rice. Krishikosh. An institutional repository of Indian National Agricultural Research system. http://krishikosh.egranth.ac.in/handle/1/ 77156.

Muhammad, S., and Amusa, N. A. 2003. In vitro inhibition of growth of some seedling blight inducing pathogens by compost inhabiting microbes. African Journal of Biotechnology, 2(6): 161164.

Shalini, N., Lata, K. P. and Kotasthane, A. S. 2006. Genetic relatedness among Trichoderma isolates inhibiting a pathogenic fungi Rhizoctonia solani. African Journal of Biotechnology. 5: 580-584.

Shylaja, M., and Rao, M. S. 2012. In vitro compatibility studies of Trichoderma harzianum with inorganic fertilizers. Nematologia Mediterranea. 40: 51-54.

Sivan, A., Elad Y. and Chet I., 1984. Biological control effects of a new isolate of Trichoderma harzianum on Pythium aphanidermatum. Phytopathology. 74: 498-501.

Sivan, A., Ucko O. and Chet I., 1987. Biological control of Fusarium crown rot of tomato by Trichoderma harzianum under field conditions. Plant Disease. 71: 587-592.

Upadhyay, J. P., and Mukhopadhyay, A. N. 1986. Biological control of Sclerotium rolfsii by Trichoderma harzianum in sugarbeet. Tropical Pest Management. 32: $215-220$.

Vincent, J.M., 1947. Distortion of fungal hyphae in the presence of certain inhibitors. Nature. 159: 850.

\section{How to cite this article:}

Kishor Chand Kumhar, A. Babu, John Peter, M. Bordoloi, Hirakjyoti Rajbongshi, Sarvesh Singh Yadav, Swagata Mani and Pritam Dey. 2017. Compatibility of Trichoderma harzianum (KBN-29) with Selected Inorganic Fertilizers: An In vitro Study. Int.J.Curr.Microbiol.App.Sci. 6(9): 2572-2578. doi: https://doi.org/10.20546/ijcmas.2017.609.316 